\title{
MODELAGEM DE ENCOLHIMENTO VOLUMÉTRICO DURANTE A DESIDRATAÇÃO OSMÓTICA DE BATATA-DOCE
}

\author{
J. R. J. JUNQUEIRA ${ }^{1 *}$, K. S. MENDONÇA ${ }^{1}$, F. J. LOPES $^{1}$, R. E. MELLO JUNIOR ${ }^{1}$, M. P. \\ FILHO $^{2}$, J. L. G. CORRÊA ${ }^{1}$ \\ ${ }^{1}$ Universidade Federal de Lavras, Departamento de Ciência dos Alimentos \\ ${ }^{2}$ Fundação Indaiatubana de Educação e Cultura \\ *e-mail: jrenatojesus@ hotmail.com
}

\begin{abstract}
RESUMO
A desidratação osmótica (DO) é um pré-tratamento que consiste na imersão de alimentos em uma solução hipertônica, ocasionando dois fluxos em contracorrente, um de perda de água do alimento para a solução e um segundo de incorporação de sólidos da solução pelo alimento. Apesar de mencionado em vários estudos, o encolhimento que ocorre durante a DO não costuma ser tratado por modelos matemáticos. O objetivo deste trabalho foi estudar a cinética de encolhimento volumétrico de fatias de batatadoce durante 300 minutos de DO. Soluções de frutose, sorbitol e sacarose, com atividade de água de 0,900 foram utilizadas como agentes osmóticos. Seis modelos empíricos da literatura foram utilizados para descrever a redução do volume com relação ao teor de umidade. Um modelo exponencial foi proposto para ajuste da cinética de encolhimento volumétrico. Tanto os modelos que relacionam a variação de volume com o teor de umidade quanto o modelo para cinética de encolhimento apresentaram-se adequados com valores elevados de $\mathrm{R}^{2}$ e baixos valores de $\chi^{2}$.
\end{abstract}

\section{INTRODUÇÃO}

A batata-doce (Ipomoea batatas (L.)) é uma das culturas mais importantes das regiões tropicais e subtropicais com diversas formas de uso. É considerada de grande importância econômico-social, participando do suprimento de calorias e minerais na alimentação humana, principalmente das populações de baixa renda (AZEVEDO et al., 2014).

A desidratação osmótica (DO) de um alimento consiste na remoção parcial de água de tecidos celulares pela sua imersão em uma solução hipertônica. Durante o processo osmótico, a transferência de massa ocorre principalmente em dois fluxos: a difusão de água do alimento para a solução osmótica e a incorporação de sólidos da solução para o alimento (CORRÊA et al., 2014).
DO é um dos pré-tratamentos mais empregados em processos na secagem de frutas e hortaliças, visando a obtenção de produtos com teores intermediários de umidade e atividade de água (FALADE; SHOGAOLU, 2010; MAYOR; MOREIRA; SERENO, 2011).

Alimentos submetidos à DO têm seu volume reduzido devido à diminuição do teor de umidade (CORRÊA et al., 2011). As modificações estruturais que ocorrem devido à desidratação são dependentes das propriedades do alimento e das condições do processo. $\mathrm{O}$ encolhimento que ocorre durante as etapas de secagem, afeta os parâmetros de transferência de calor e de massa, sendo um fator importante a ser considerado na modelagem (SEGUí et al., 2010; SEGUÍ et al., 2012). 
O objetivo deste trabalho foi investigar o encolhimento volumétrico durante a desidratação osmótica de fatias de batatadoce. Empregou-se três diferentes agentes osmóticos (frutose, sorbitol e sacarose) em solução com atividade de água 0,900. Os dados experimentais de encolhimento volumétrico em função do teor de umidade foram ajustados por modelos da literatura e um modelo exponencial foi proposto para ajuste da cinética de encolhimento volumétrico.

\section{MATERIAL E MÉTODOS}

\subsection{Material}

A batata-doce (Ipomoea batatas (L.)) cv. Braslândia branca utilizada nos experimentos de desidratação osmótica foi adquirida no comércio local (Lavras, MG, Brasil) e armazenada em refrigerador à $7 \pm 1^{\circ} \mathrm{C}$. As raízes foram selecionadas com base em características uniformes de maturação, cor, diâmetro, firmeza e sem danos físicos, visando minimizar as diferenças na amostragem. $O$ teor inicial de umidade foi de $0,70 \mathrm{~kg}$ de água $/ \mathrm{kg}$ amostra, determinado pela secagem em estufa à vácuo a $70^{\circ} \mathrm{C}$ até peso constante (AOAC, 2007).

\subsection{Preparação das Amostras e Solução Osmótica}

As raízes foram lavadas, descascadas manualmente e cortadas em fatias de $2,00 \mathrm{~cm}$ de comprimento $\times 2,00 \mathrm{~cm}$ de largura $\times 0,50$ $\mathrm{cm}$ de espessura, com auxílio de uma faca e um molde de aço inox, em seguida foram imersas por 3 minutos em solução aquosa de ácido cítrico $1 \%(\mathrm{p} / \mathrm{v})$ para minimizar escurecimento enzimático (MENDONÇA et al., 2015).

As soluções osmóticas foram preparadas com água destilada e os agentes osmóticos empregados foram frutose, sorbitol e sacarose comerciais. A concentração e o peso molecular dos agentes estão apresentados na tabela 1 . A atividade de água $\left(a_{w}\right)$ das soluções foi $0,900 \pm 0,003$.

Tabela 1 - Peso molecular (P.M.) dos agentes osmóticos e concentração das soluções

\begin{tabular}{lll}
\hline $\begin{array}{l}\text { Agente } \\
\text { osmótico }\end{array}$ & $\begin{array}{l}\text { P.M. } \\
{\left[\mathrm{kg} \mathrm{kmol}^{-1}\right]}\end{array}$ & $\begin{array}{l}\text { Concentração } \\
{\left[{ }^{\circ} \text { Brix }\right]}\end{array}$ \\
\hline Frutose & 180,16 & 52,1 \\
Sorbitol & 182,17 & 52,4 \\
Sacarose & 342,29 & 60,0 \\
\hline
\end{tabular}

\subsection{Desidratação Osmótica (DO)}

Os experimentos de DO foram realizados pela imersão das amostras em erlenmeyers de $100 \mathrm{~mL}$ contendo a solução osmótica na proporção raiz:solução de 1:10 $(\mathrm{p} / \mathrm{p})$. Esta proporção alimento:solução foi utilizada para evitar alterações significativas na solução osmótica (VIANA; CORRÊA; JUSTUS, 2014). Os erlenmeyers foram codificados para identificação das amostras durante a DO. Os experimentos foram realizados à pressão atmosférica $\mathrm{e}$ temperatura de $30 \pm 0,5^{\circ} \mathrm{C}$. A temperatura foi mantida constante em uma câmara de controle de temperatura (ELETROlab, EL 111/4, São Paulo, Brasil). Os experimentos foram realizados em quintuplicata e o valor médio, reportado.

A determinação da variação de volume das amostras foi feita com a remoção das mesmas em tempos pré-determinados $(15,30$, $45,60,90,120,150,180,240$ e 300 minutos) para medidas de área e espessura, com retorno das amostras à solução após as medições.

A determinação do teor de umidade das amostras foi conduzida em paralelo com a retirada de amostras em cada tempo prédeterminado, de acordo com o método AOAC 934.06 (AOAC, 2007).

\subsection{Análises Analíticas}

A área das amostras foi determinada através de análise de imagem com auxílio do 
software Image $\mathrm{J}^{\circledR} 1.45 \mathrm{~s}$. O software fornece a área da amostra pela conversão dos pixels na imagem em dimensões reais, a partir de uma escala conhecida (LOPES, 2013). A espessura das amostras foi medida em cinco pontos distintos com auxílio de um paquímetro digital calibrado (Western, modelo DC-6, China) e tomada a média aritmética das medidas.

O volume das amostras foi obtido pela multiplicação da área superficial fotografada pela espessura média.

$\mathrm{O}$ encolhimento foi relacionado ao volume adimensional, $\beta$, determinado pela razão entre o volume da amostra desidratada,
$\mathrm{V}$ pelo volume da amostra fresca, $\mathrm{V}_{0}$ conforme Equação 1:

$$
\beta=\frac{V}{V_{0}}
$$

\subsection{Modelagem do Encolhimento}

2.5.1 Encolhimento em Função do Teor de Umidade

Os modelos da literatura apresentados na Tabela 2 foram utilizados para ajustar a relação entre o encolhimento e o teor de umidade das amostras.

Tabela 2 - Modelos matemáticos aplicados à predição do encolhimento volumétrico $(\beta)$ de batata-doce com relação ao teor de umidade $(\mathrm{X})$

\begin{tabular}{ll}
\hline Equação: $\beta=V / V_{0}$ & Referências \\
\hline$\beta=1-a\left(X-X_{0}\right)$ & Yaldiz e Ertekin (2001) \\
$\beta=1-a\left(1-\exp \left(b\left(X-X_{0}\right)\right)\right)$ & Yaldiz, Ertekin e Uzun (2001) \\
$\beta=1 /(a+b \exp (X))$ & Ertekin e Yaldiz (2004) \\
$\beta=1-a\left(1-\exp \left(b\left(X-X_{0}\right)\right)\right)$ & Ratti (1994) \\
$\beta=a+b\left(X-X_{0}\right)+c \exp \left(d\left(X / X_{0}\right)\right)$ & Lozano, Rotstein e Urbicain (1983) \\
$\beta=a+b X+c X^{2}+d X^{3}$ & Ratti (1994) \\
\hline
\end{tabular}

\subsubsection{Cinética de Encolhimento}

Um modelo exponencial relacionando o encolhimento e o tempo do processo também foi proposto no presente trabalho.

A formulação do modelo foi feita considerando-se que a grande maioria dos fenômenos que envolvem cinéticas de materiais biológicos apresentam perfis exponenciais.

Desta forma, o modelo é uma adaptação do modelo de Page (1949) para o encolhimento, apresentado pela Equação 8.

$$
\beta=\exp \left(-k t^{n}\right)
$$

Onde: $\mathrm{k}$ e $\mathrm{n}$ representam constantes do modelo e $\mathrm{t}$ representa o tempo do processo (minutos).

\subsubsection{Análise Estatística}

Uma análise de regressão não-linear foi conduzida para o ajuste aos modelos matemáticos, utilizando o métodos de QuasiNewton, com auxílio do software Statistica $7.0^{\circledR}$ (Statsoft, Tulsa, OK). 
O critério para avaliação da adequação do modelo aos dados experimentais de desidratação foi o coeficiente de correlação $\left(\mathrm{R}^{2}\right)$. Além disso, foram avaliados o valor de chi-quadrado $\left(\chi^{2}\right)$ e a raiz média do quadrado de erro (RMQE) para determinar a qualidade do ajuste. Esses parâmetros estatísticos podem ser calculados de acordo com as equações 9 e 10.

$$
\begin{aligned}
& \chi_{2}=\sum_{i=1}^{N} \frac{\left(I_{\text {exp }, i}-I_{\text {pred }, i}\right)^{2}}{N-n^{\prime}} \\
& R M Q E=\sqrt{\left[\frac{1}{N} \sum_{i=1}^{N}\left(I_{p r e, i}-I_{\text {exp }, i}\right)^{2}\right]}
\end{aligned}
$$

\section{RESULTADOS E DISCUSSÃO}

\subsection{Encolhimento em Função do Teor de Umidade}

A Tabela 3 apresenta os parâmetros de ajuste de modelos que relacionam o volume adimensional $\left(\beta=\mathrm{V} / \mathrm{V}_{0}\right)$ ao teor de umidade. Pela observação da tabela, o modelo que melhor se ajustou aos dados experimentais de desidratação osmótica de batata-doce com maiores valores de $\mathrm{R}^{2}$ e menores valores de $\chi^{2}$ e RMQE foi o modelo polinomial proposto por Ratti (1994). Segundo os testes aplicados, o modelo apresentou os seguintes valores médios: $\quad \mathrm{R}^{2} \geq 0,8971, \quad \chi^{2} \leq 0,00259 \quad \mathrm{e}$ $\mathrm{RMQE} \leq 0,0394$.

\begin{tabular}{|c|c|c|c|c|}
\hline & Constantes & Frutose & Sorbitol & Sacarose \\
\hline \multirow{4}{*}{ Yaldiz e Ertekin (2001) } & $\mathrm{a}$ & $-0,2696$ & $-0,2672$ & $-0,3474$ \\
\hline & $\mathrm{R}^{2}$ & 0,7736 & 0,9820 & 0,9715 \\
\hline & $\chi^{2}$ & $3,79 \times 10^{-3}$ & $5,00 \times 10^{-4}$ & $9,16 \times 10^{-4}$ \\
\hline & RMQE & $5,84 \times 10^{-2}$ & $2,13 \times 10^{-2}$ & $2,87 \times 10^{-2}$ \\
\hline \multirow{5}{*}{$\begin{array}{l}\text { Yaldiz, Ertekin e Uzun } \\
\qquad(2001)\end{array}$} & $\mathrm{a}$ & 500,000 & 499,992 & 499,999 \\
\hline & $\mathrm{b}$ & $5,4 \times 10^{-4}$ & $5,35 \times 10^{-4}$ & $6,95 \times 10^{-4}$ \\
\hline & $\mathrm{R}^{2}$ & 0,7736 & 0,9822 & 0,9716 \\
\hline & $\chi^{2}$ & $4,27 \times 10^{-3}$ & $5,69 \times 10^{-4}$ & $1,03 \times 10^{-3}$ \\
\hline & RMQE & $5,84 \times 10^{-2}$ & $2,13 \times 10^{-2}$ & $2,86 \times 10^{-2}$ \\
\hline \multirow{5}{*}{ Ertekin e Yaldiz (2004) } & $\mathrm{a}$ & 1,6885 & 1,7580 & 2,1014 \\
\hline & $\mathrm{b}$ & $-0,0394$ & $-0,0449$ & $-0,0627$ \\
\hline & $\mathrm{R}^{2}$ & 0,8212 & 0,7663 & 0,8618 \\
\hline & $\chi^{2}$ & $3,37 \times 10^{-3}$ & $7,47 \times 10^{-3}$ & $5,00 \times 10^{-3}$ \\
\hline & RMQE & $5,19 \times 10^{-2}$ & $7,73 \times 10^{-2}$ & $6,33 \times 10^{-2}$ \\
\hline Ratti (1994) & $\mathrm{a}$ & 0,2772 & 0,2001 & 0,0409 \\
\hline
\end{tabular}

Tabela 3 - Relação entre encolhimento volumétrico e teor de umidade 
Lozano, Rotstein e

Urbicain (1983)

Ratti (1994)

$\begin{array}{cccc}\mathrm{b} & 0,6827 & 0,8211 & 0,9189 \\ \mathrm{R}^{2} & 0,7953 & 0,9860 & 0,9837 \\ \chi^{2} & 3,86 \times 10^{-3} & 4,48 \times 10^{-4} & 5,90 \times 10^{-4} \\ \mathrm{RMQE} & 5,55 \times 10^{-2} & 1,89 \times 10^{-2} & 2,17 \times 10^{-2} \\ \mathrm{a} & -11,1140 & 0,1669 & 0,0999 \\ \mathrm{~b} & -5,4188 & 0,9716 & 0,8085 \\ \mathrm{c} & 11,9473 & -0,0127 & 0,0000 \\ \mathrm{~d} & 0,3866 & 2,3278 & 10,7516 \\ \mathrm{R} & 0,8630 & 0,9876 & 0,9946 \\ \chi^{2} & 3,44 \times 10^{-3} & 5,25 \times 10^{-4} & 2,60 \times 10^{-4} \\ \mathrm{RMQE} & 4,54 \times 10^{-2} & 1,77 \times 10^{-2} & 1,25 \times 10^{-2} \\ & & & \\ \mathrm{a} & 3,4916 & 0,2809 & -0,4187 \\ \mathrm{~b} & -4,3087 & 0,1074 & 1,1804 \\ \mathrm{c} & 2,0477 & 0,1138 & -0,5049 \\ \mathrm{~d} & -0,2958 & -0,0223 & 0,0919 \\ \mathrm{R}^{2} & 0,8971 & 0,9878 & 0,9968 \\ \chi^{2} & 2,59 \times 10^{-3} & 5,17 \times 10^{-4} & 1,50 \times 10^{-4} \\ \mathrm{RMQE} & 3,94 \times 10^{-2} & 1,76 \times 10^{-2} & 9,49 \times 10^{-3}\end{array}$

Dentre os agentes osmóticos testados, a frutose foi o que apresentou pior ajuste (Tabela 3). De modo geral, o modelo proposto por Ertekin e Yaldiz (2004), foi o que apresentou menores valores de $\mathrm{R}^{2}$ e maiores valores de $\chi^{2}$ e RMQE.

Para os tratamentos com sacarose e sorbitol, todos os modelos propostos (exceto o modelo de Ertekin e Yaldiz (2004)) apresentaram valores de coeficiente de correlação maiores que 0,970 , indicando bons ajustes aos modelos preditivos.

Toĝrul e Ispir (2007) também propuseram a aplicação destes seis modelos na predição do encolhimento de damascos durante a desidratação osmótica com diferen- tes agentes osmóticos (sacarose, frutose, glicose, maltodextrina e sorbitol), e concluíram que a maioria dos modelos apresentaram bons ajustes aos dados experimentais.

\subsection{Cinética de Encolhimento}

O modelo exponencial proposto para correlacionar a redução no volume (adimensional) e o tempo (minutos), as constantes e os parâmetros estatísticos estão apresentados na Tabela 4.

O proposto modelo empírico apresentou bom ajuste aos dados experimentais quando a sacarose e o sorbitol foram empregados como 
agentes osmóticos, com $\mathrm{R}^{2}$ superiores a 0,98, $\chi^{2}$ menores que 0,001 e RMQE menores que 0,04 .

Tabela 4 - Constantes do modelo exponencial e parâmetros estatísticos

\begin{tabular}{lccc}
$\begin{array}{l}\text { Modelo: } \\
\beta=\exp \left(-k t^{n}\right)\end{array}$ & Frutose & Sorbitol & Sacarose \\
\hline $\mathrm{k}$ & 0,0651 & 0,0267 & 0,0625 \\
$\mathrm{n}$ & 0,3556 & 0,5826 & 0,4651 \\
$\mathrm{R}^{2}$ & 0,9109 & 0,9815 & 0,9901 \\
$\chi^{2}$ & 0,0015 & 0,0006 & 0,0003 \\
$\mathrm{RMQE}$ & 0,0348 & 0,0218 & 0,0161 \\
\hline
\end{tabular}

Conclui-se que o modelo exponencial representa adequadamente o fenômeno de encolhimento para a desidratação osmótica para estes agentes. $\mathrm{O}$ tratamento em que a frutose foi empregada apresentou maiores valores de RMQE e baixos valores de $\mathrm{R}^{2}$, mas ainda foi possível explicar a relação existente entre a redução volumétrica e o tempo.

A abordagem exponencial para a cinética de desidratação conforme Page (1949) é uma das que fornece melhores ajustes (AZIZPOUR et al., 2014; TASIRIN et al., 2013). Como observado neste e em outros trabalhos (MAYOR; SERENO, 2004), o encolhimento está diretamente relacionado ao teor de umidade.

Desta forma, o uso da equação de Page (1949) na predição do encolhimento, levou a resultados bastante pertinentes.

\section{CONCLUSÃO}

O encolhimento em desidratação osmótica de fatias de batata-doce pode ser relacionado à variação do teor de umidade e sua cinética apresenta comportamento exponencial.

\section{NOMENCLATURA}

Símbolo
$\mathrm{a}_{\mathrm{w}}$
$\mathrm{a}, \mathrm{b}, \mathrm{c} \mathrm{e}$
$\mathrm{d}$
$\mathrm{I}_{\text {exp }}$
$\mathrm{I}_{\text {pre }}$
$\mathrm{k}$
$\mathrm{N}$
$\mathrm{n}$
$\mathrm{t}$
$\mathrm{V}_{0}$
$\mathrm{~V}$

$\mathrm{X}$

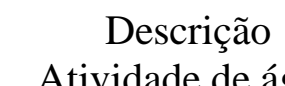

Unidade

Atividade de água

Constantes dos modelos

Valores obtidos

experimentalmente

Valores preditos pelos modelos

Coeficiente de secagem

Número de

observações

Número de constantes Tempo

$\min$

Volume da amostra fresca

Volume da amostra desidratada

$\mathrm{cm}^{3}$

$\mathrm{cm}^{3}$

$\mathrm{kg}$ de

Teor de umidade

água/kg

de

amostra

$\mathrm{kg}$ de

Teor de umidade inicial água/kg de amostra

\section{REFERÊNCIAS}

A.O.A.C. (ASSOCIATION OF OFFICIAL ANALYTICAL CHEMISTS). Official methods of analysis. 18.ed. Washington: AOAC, 2007. 3000p.

ANTONIO, G. C. et al. Osmotic dehydration of sweet potato (Ipomoea batatas) in ternary solutions. Ciência e Tecnologia de Alimentos, v. 28, p.696-701, 2008.

AZEVEDO, A. et al. Influence of harvest time and cultivation sites on the productivity and quality of sweet potato. Horticultura Brasileira, v. 32, p.21-27, 2014. 
AZIZPOUR, M. et al. Optimization of Foaming Parameters and Investigating the Effects of Drying Temperature on the FoamMat Drying of Shrimp (Penaeus indicus). Drying Technology, v. 32, p.374-384, 2014.

CORRÊA, J. L. G. et al. Drying of pineapple by microwave-vacuum with osmotic pretreatment. Drying Technology, v. 29, p.1556-1561, 2011.

CORRÊA, J. L. G. et al. Optimisation of vacuum pulse osmotic dehydration of blanched pumpkin. International Journal of Food Science \& Technology, v. 49, p.20082014, 2014.

ERTEKIN, C.; YALDIZ, O. Drying of eggplant and selection of a suitable thin layer drying model. Journal of Food Engineering, v. 63, p.349-359, 2004.

FALADE, K. O.; SHOGAOLU, O. T. Effect of pretreatments on air-drying pattern and color of dried pumpkin (Cucurbita Maxima) slices. Journal of Food Process Engineering, v. 33, p.1129-1147, 2010.

KATEKAWA, M. E.; SILVA, M. A. Drying rates in shrinking medium: case study of banana. Brazilian Journal of Chemical Engineering, v. 24, p.561-569, 2007.

LOPES, F. J. Estudo do fenômeno de encolhimento na secagem convectiva de abacaxi com aplicação de micro-ondas. 2013. 147 p. Dissertação (Mestrado em Produção Vegetal) - Universidade Estadual do Norte Fluminense Darcy Ribeiro, Campos dos Goytacazes, 2013.

LOZANO, J. E.; ROTSTEIN, E.; URBICAIN, M. J. Shrinkage, porosity and bulk density of foodstuffs at changing moisture contents. Journal of Food Science, v. 48, p.1497-1553, 1983.
MAYOR, L.; MOREIRA, R.; SERENO, A. M. Shrinkage, density, porosity and shape changes during dehydration of pumpkin (Cucurbita pepo L.) fruits. Journal of Food Engineering, v. 103, p.29-37, 2011.

MAYOR, L.; SERENO, A. M. Modelling shrinkage during convective drying of food materials: a review. Journal of Food Engineering, v. 61, p.373-386, 2004.

MENDONÇA, K. S. et al. Optimization of osmotic dehydration of yacon slices. Drying Technology, In Press, Accepted Manuscript, 2015.

MOREIRA, R. et al. Water absorption, texture, and color kinetics of air-dried chestnuts during rehydration. Journal of Food Engineering, v. 86, p.584-594, 2008.

NAHIMANA, $H$. et al. Mass Transfer Modeling and Shrinkage Consideration during Osmotic Dehydration of Fruits and Vegetables. Food Reviews International, v. 27, p.331-356, 2011.

OLIVER, L. et al. How to deal with viscoelastic properties of cellular tissues during osmotic dehydration. Journal of Food Engineering, v. 110, p.278-288, 2012.

PAGE, C. Factors influencing the maximum rates of air drying shelled corn in thin layer. Unpublished MS Thesis, Purdue University, Lafayette, IN, 1949.

SEGUÍ, L.; FITO, P. J.; FITO, P. Understanding osmotic dehydration of tissue structured foods by means of a cellular approach. Journal of Food Engineering, v. 110, p.240-247, 2012.

SEGUÍ, L.; FITO, P. J.; FITO, P. Analysis of structure-property relationships in isolated cells during OD treatments. Effect of initial 
structure on the cell behaviour. Journal of Food Engineering, v. 99, p.417-423, 2010.

StatSoft Inc. Statistica ${ }^{\circledR} 7.0$ User's Guide. Tulsa, OK, USA: StatSoft Inc. 2007.

TASIRIN, S. M. et al. Drying of Citrus sinensis Peels in an Inert Fluidized Bed: Kinetics, Microbiological Activity, Vitamin C, and Limonene. Drying Technology, v. 32, p.497-508, 2014.

TOĞRUL, İ. T.; İSPIR, A. Effect on effective diffusion coefficients and investigation of shrinkage during osmotic dehydration of apricot. Energy Conversion and Management, v. 48, p.2611-2621, 2007.

VIANA, A. D.; CORRÊA, J. L. G.; JUSTUS, A. Optimisation of the pulsed vacuum osmotic dehydration of cladodes of fodder palm. International Journal of Food Science \& Technology, v. 49, p.726-732, 2014.

YALDIZ, O.; ERTEKIN, C. Thin layer solar drying of some vegetables. Drying Technology, v. 19, p.583-597, 2001.

YALDIZ, O.; ERTEKIN, C.; UZUN, H. I. Mathematical modeling of thin layer solar drying of sultana grapes. Energy, v. 26, p.457-465, 2001.

\section{AGRADECIMENTOS}

Os autores agradecem ao CNPq, à CAPES e à FAPEMIG, pelo apoio financeiro. 